her nur national angeboten werden konnten, international gehandelt werden.

\section{Voraussetzungen geschaffen}

Als erste TSO (Transmission System Operators) in Europa haben die APG und RWE-Net die technischen und organisatorischen Voraussetzungen geschaffen, um zwischen den Regelblöcken Österreich und
Deutschland elektrische Energie im Zeitintervall von $15 \mathrm{Mi}-$ nuten mit einer kleinsten Auflösung von $1 \mathrm{~kW}$ auszutauschen. Bisher war dies nur mit Fahrplänen im 1-Stunden-Raster mit einer Auflösung von 100 kW möglich, während in den Regelzonen selbst die Ermittlung der Ausgleichsenergie jedoch vornehmlich auf Viertelstunden-Basis und in kWh erfolgt.
Mit der bisherigen Regelung war die Belieferung von Kunden durch Lieferanten und Händler, die ihre Energie außerhalb der Regelzone aufbringen, nur erschwert möglich, denn bei einer die Regelzonengrenzen überschreitenden Vollversorgung von gemessenen Verbrauchern sowie bei der Belieferung von Profil-Kunden (Haushalte und Gewerbe) fiel zwangsläufig ein erheblicher Anteil von Ausgleichsenergie an.

Die Einführung des MultiTime-Frame-Systems (MTFS) ist darüber hinaus auch ein wichtiger Schritt zur Realisierung eines die Regelzonengrenzen überschreitenden Anbietermarktes für Ausgleichsenergie.

Informationen: Verbundgesellschaft, Am Hof 6A, A-1010 Wien, Telefon: +43 (1) 531130 , Internet: www.verbund.at

\title{
HOCHWASSERHILFE
}

\section{Sachspendenaktion durch Festo-Mitarbeiter}

\begin{abstract}
Obwohl nach der Hochwasserkatastrophe vom Sommer für viele Menschen bereits wieder der Alltag eingekehrt ist, kämpfen manche der Betroffenen noch immer mit den Folgen dieser Flut. Die Betriebsratsvorsitzende der Firma Festo, Ursula Mitsche, hat angesichts des Katastrophenausmaßes,erkannt, dass den Menschen, die alles verIoren haben, geholfen werden muss. Sie hat daher prompt reagiert und schon Ende August die Mitarbeiter von Festo um Sachspenden für die Gemeinde Haderșdorf am Kamp gebeten. In kurzer Zeit ist es gelungen, Sachspenden im
\end{abstract}

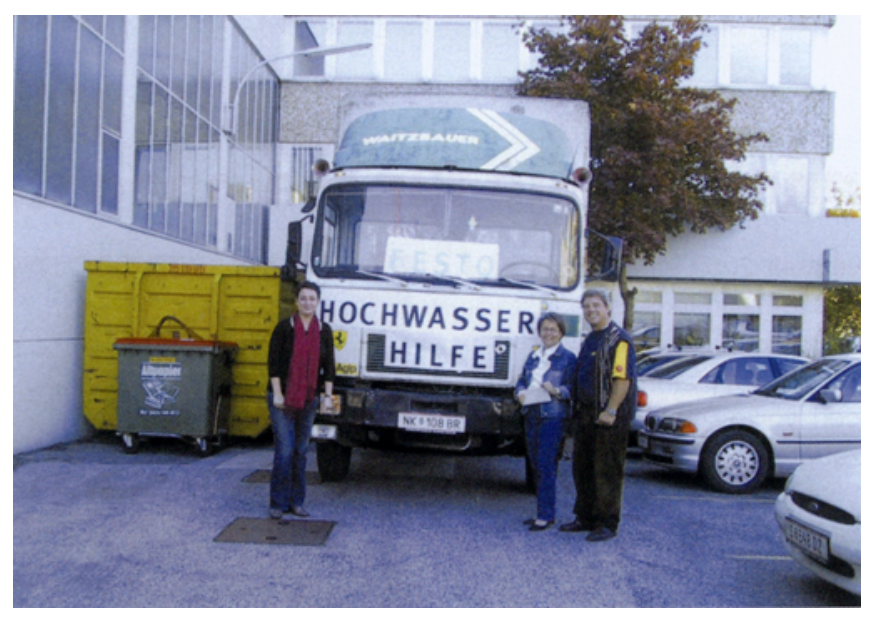

Sachspendentransport der Festo-Mitarbeiter, mit Unterstützung von B. Böcskör, U. Mitsche, beide Festo, und einem Mitarbeiter der Spedition Weiss (v.l.n.r.)
Wert von etwa 10.000,- Euro zu sammeln. Ein Betroffener kann sich unter anderem über ein komplettes Badezimmer freuen. Besonders erfreulich war, dass die Mitarbeiter noch zusätzlich ca. 500,Euro an Geldspenden aufbrachten.

Ausgeliefert wurden die Sachspenden Ende Oktober. Die Spedition Johann Weiss aus Wr. Neudorf hat sich spontan bereit erklärt, den Transport kostenlos zu übernehmen.

Informationen: Festo GesmbH, Katharina Böcskör, Lützowgasse 14, A1141 Wien, Telefon +43 (1) $91075-$

114 , Internet: www.festo.at lagen vermittelt das Buch in kompakter und übersichtlicher Form Spezialwissen und Anwendungen aus Physik, Chemie, Verfahrenstechnik, Elektrotechnik, Maschinenbau, Umwelttechnik und Werkstofftechnik. Der interdisziplinäre Aufbau würdigt auch die Inhalte der jüngst entstandenen Studiengănge mit Systemcharakter und regt zu vernetztem Denken an.

Kurzweil, Peter: Das Vieweg Formel-Lexikon. Wiesbaden: Vieweg 2002. 594 S., $\in$ 39.90. ISBN: 3-528-03950-7.

\section{Mikrorechner-Technik}

Dieses zweibändige Lehrbuch bietet eine verständliche Einführung in den Aufbau und die Funktionsweise von Mikrorechnern, $d . h$. von universell einsetzbaren und programmierbaren Digitalrechnern, die als Kern einen oder mehrere Mikroprozessoren enthalten. Der zweite Band befasst sich mit den Komponenten, die einen Mikroprozessor zu einem Mikrorechner erweitern.

Im Einzelnen werden Eingabe- und Ausgabebusse, die Organisation und Verwaltung des Arbeitsspeichers sowie die wichtig- sten Steuer- und Schnittstellenbausteine behandelt.

Weiterhin wird die Funktionsweise von Mikrocontrollern erlăutert; dies sind vollstăndige Mikrorechner, die auf einem einzigen Halbleiterchip integriert sind. Anhand umfassender Fallstudien werden die vielfach verwendeten Bausteine, insbesondere der Firmen Intel, Motorola und Analog Devices detailliert beschrieben. Das Buch richtet sich vor allem an Studierende der Informatik, Elektronik, Elektrotechnik und Kommunikationstechnik.

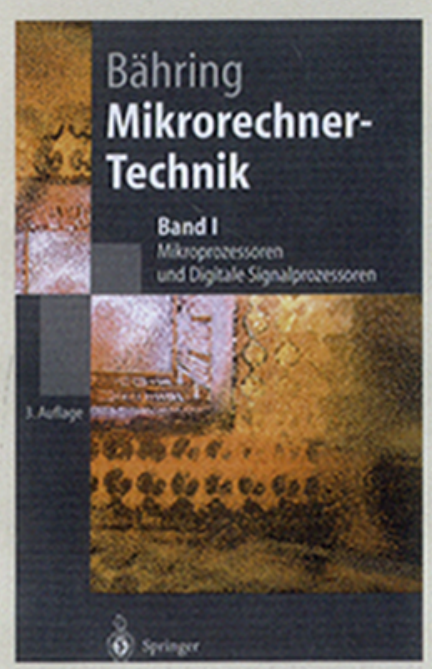

